\title{
Instituições centrais de auditoria \\ e auditoria de desempenho: uma análise comparativa das estratégias organizacionais na $\mathrm{OCDE}^{*}$
}

A auditoria de desempenho ${ }^{1}$ vem sendo rapidamente aceita como um tipo de atividade profissional de revisão governamental ex-post. Essa categoria envolve tanto alguns tipos familiares de trabalhos de revisão, como as auditorias de eficiência e as de efetividade, quanto formas menos conhecidas, como as auditorias de informação, geradas pelos sistemas de gerenciamento de desempenho. O surgimento dessa nova categoria no vocabulário da administração pública indica que o processo de demarcação de um novo domínio da atividade burocrática está em andamento. A teoria sociológica neo-institucionalista (Meyer e Rowan, 1991) sugere que, à medida que a auditoria de desempenho se tornar mais institucionalizada, $o$ nível dessa atividade deve aumentar, provavelmente seguido pela criação de subdivisões distintas ou pela expansão das linhas de produto.

São várias as organizações que desenvolvem e realizam trabalhos de auditoria de desempenho. No Reino Unido, pode-se citar a Audit Comission for England and Wales (Comissão de Auditoria para a Inglaterra e País de Gales), cuja jurisdição inclui o governo municipal, o Serviço Nacional de Saúde e a polícia; o National Audit Office (NAO), cuja jurisdição compreende o restante do governo central; e uma gama de inspetorias de setores ou órgãos específicos em rápida expansão, como o Office of Standards in Education (Escritório de Normas para a Educação Hood e Scott, 1996). Nos Estados Unidos da América do Norte (EUA), entre as entidades que conduzem trabalhos de auditoria de desempenho, pode-se destacar os Office of Inspectors General (Escritórios dos Inspetores Gerais) e o General Accounting Office - GAO (Escritório do Auditor-Geral — Trodden, 1995; Walsh, 1996). Assim, a racionalização, a produção e a expansão nessa área de estudo podem ser observadas, até o
Michael

Barzelay é professor da London School of Economics and Political Science, Reino Unido.

Contato: m.barzelay@ $\underline{\text { lse.ac.uk }}$

Traduzido por Adriana Monteiro Vieira e Marcelo Barros Gomes 
momento, no âmbito da área organizacional, na qual essas instituições estão inseridas (DiMaggio e Powell, 1991). As organizações governamentais fundamentais na área de auditoria de desempenho incluem aquelas responsáveis pela elaboração orçamentária, auditoria, avaliação e reforma administrativa, inclusive o Public Management Service - PUMA (Serviço de Administração Pública) ${ }^{2}$ da Organização para a Cooperação e o Desenvolvimento Econômico (OCDE).

Este trabalho concentra sua análise no nível organizacional dos órgãos centrais de auditoria, algumas vezes denominados Entidades Fiscalizadoras Superiores (EFS), conforme estabelece sua associação internacional. Tais organizações incluem a Agência Nacional de Auditoria da Suécia, a Corte de Contas da Alemanha, o Escritório Nacional de Auditoria do Reino Unido (NAO), o Escritório do Auditor-Geral do Canadá, a Corte de Contas da França e o Escritório do Auditor-Geral dos Estados Unidos (GAO). A forma pela qual os órgãos de auditoria lidam com a institucionalização da auditoria de desempenho muito provavelmente terá efeito significativo sobre a escala e a distribuição das atividades de revisão na esfera governamental. Tais reações tenderão a delinear o modo de operação e o impacto dos sistemas governamentais de responsabilização e prestação de contas (accountability). ${ }^{3}$

Neste artigo, propõe-se realizar uma análise comparativa inicial sobre os trabalhos de auditoria de desempenho conduzidos por órgãos centrais de auditoria da OCDE. A principal questão para a pesquisa descritiva diz respeito ao grau de uniformidade ou de variação existente entre as políticas organizacionais desses órgãos, no que concerne à auditoria de desempenho. Para esse propósito, foram analisados dados obtidos pelo PUMA. $\mathrm{O}$ trabalho desenvolve uma explicação institucional para as variações observadas nas políticas organizacionais dos diferentes órgãos centrais de auditoria. Além disso, são analisadas as escolhas estratégicas quanto à implementação da auditoria de desempenho, que se impõem aos órgãos centrais de auditoria. ${ }^{4}$

\section{$O$ conceito da auditoria de desempenho}

O termo auditoria de desempenho é normalmente utilizado para demarcar a distinção entre esse tipo de atividade de revisão governamental e a auditoria tradicional; e a avaliação de programas. A forma como essa distinção é feita tem implicações sobre qual categoria profissional possui os argumentos mais persuasivos com o intuito de obter o controle jurisdicional da matéria. Os funcionários de alguns órgãos centrais de auditoria tendem a destacar as semelhanças entre a auditoria tradicional 
e a de desempenho (Sedgwick, 1993), provavelmente com o intuito de manter ou expandir sua fatia de mercado na indústria da revisão governamental. Os especialistas em avaliação, por seu turno, tendem a caracterizar a auditoria de desempenho como uma forma de avaliação (Chelimsky, 1985; Rist, 1989), talvez pela mesma razão. Assim, como a questão da disputa pelo controle da atividade ainda persiste, também não existe consenso quanto ao significado exato do conceito de auditoria de desempenho.

A maioria dos estudiosos sobre a matéria define a auditoria de desempenho de forma a refletir as realidades institucionais de seus próprios países. Aqueles que escrevem no contexto institucional do governo britânico (Westminster/Whitehall) tendem a estabelecer uma distinção entre política e administração dentro da definição de auditoria de desempenho. Ao passo que, aqueles que escrevem no contexto de um regime de poder partilhado entre o Executivo e o Legislativo, como ocorre nos EUA, agem de forma diferente. Assim, de certa maneira, as divergências de visão sobre o conceito de auditoria de desempenho devem-se à tendência natural de se tomar realidades locais por padrões universais.

Um esforço para demarcar a distinção entre esses conceitos, de cunho isento e de aplicabilidade universal, exige uma análise conceitual cuidadosa. A análise aqui apresentada irá indicar, entre outros aspectos conceituais, que as auditorias de desempenho não são um tipo de auditoria, elas são, de fato, avaliações. Entretanto, diferentemente das avaliações de programas convencionais, as auditorias de desempenho são freqüientemente realizadas de forma similar a uma auditoria. É uma questão de escolha estratégica da organização, não praticada universalmente, adotar processos de trabalho similares à auditoria para realizar suas avaliações. Assim, o estilo de trabalho da atividade de auditoria não deve ser considerado parte do sentido central do conceito de auditoria de desempenho.

Para se chegar a essas distinções, ao mesmo tempo sutis e contundentes, este trabalho adota a teoria de conceitos e categorias formulada por George Lakoff (1987), especialista em lingüística cognitiva da Universidade de Berckley, Califórnia. ${ }^{5}$ Conforme essa teoria, palavras são nomes para conceitos. O significado de conceitos abstratos e complexos, como as categorias da atividade de revisão governamental, não pode ser descrito em uma linha ou duas, como em uma definição de dicionário, ou mesmo pela enumeração de algumas de suas propriedades essenciais. Para se analisar o significado desses conceitos, é crucial que se identifique os vários modelos cognitivos idealizados que juntos caracterizam o conceito (op.cit., 1987: 68). A seguir, será apresentada uma proposta de caracterização do conceito denominado auditoria de desempenho. Cabe ressaltar, a princípio, três aspectos dessa caracterização. Primeiro, os modelos 
cognitivos idealizados aqui selecionados permitem a diferenciação dos conceitos de auditoria de desempenho dos conceitos de auditoria tradicional e de avaliação de programas. Segundo, a caracterização da auditoria de desempenho também serve de parâmetro para o significado de suas categorias subordinadas (i.e., os tipos existentes de auditoria de desempenho, tais como as auditorias de eficiência). Terceiro, a caracterização de auditoria de desempenho aqui proposta permite especificações mais detalhadas que comportem diferentes realidades locais e orientações doutrinárias.

O significado do conceito de auditoria de desempenho caracteriza-se por uma série de Modelos Cognitivos Idealizados (MCIs) inter-relacionados referentes ao funcionamento de governo, ao tipo de funcionamento desejado, ao principal objetivo da revisão, à modalidade dominante de revisão e ao papel do revisor auditor. A mesma lógica aplica-se ao significado dos conceitos de auditoria tradicional e de avaliação de programas. Em outras palavras, os sentidos centrais dos conceitos associados à auditoria tradicional, auditoria de desempenho e avaliação de programas podem ser formulados com base em modelos que variam de acordo com cinco dimensões (Quadro 1).

\section{Quadro 1: Comparação entre auditoria tradicional,} auditoria de desempenho e avaliação de programas

\begin{tabular}{|c|c|c|c|c|c|}
\hline & $\begin{array}{l}\text { Intigese de } \\
\text { ascrerae }\end{array}$ & $\begin{array}{l}\text { limagem } \\
\text { de hom } \\
\text { funodonamento }\end{array}$ & $\begin{array}{l}\text { Ohjodive } \\
\text { prtacipal da } \\
\text { rovtsuio }\end{array}$ & $\begin{array}{l}\text { Mloibalidade } \\
\text { predeanatinante }\end{array}$ & $\begin{array}{l}\text { Pupel div reviunt } \\
\text { adator }\end{array}$ \\
\hline $\begin{array}{l}\text { Audiloria } \\
\text { tradiclonal }\end{array}$ & $\begin{array}{l}\text { Mictuinta } \\
\text { beroctitioa. }\end{array}$ & 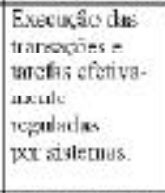 & $\begin{array}{l}\text {-Aecowniabdizy } \\
\text { de } \\
\text { omformidats. }\end{array}$ & Sulitcria & 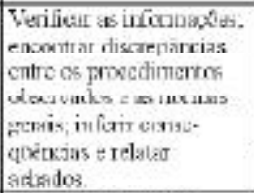 \\
\hline $\begin{array}{l}\text { Auditoria de } \\
\text { desempenbu }\end{array}$ & 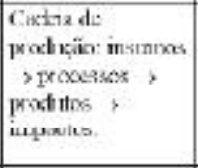 & 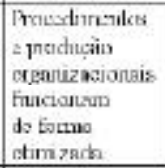 & 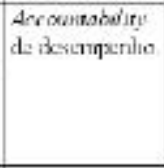 & 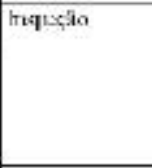 & 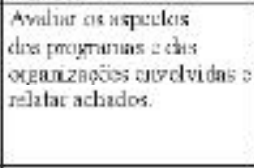 \\
\hline $\begin{array}{l}\text { Avaltaciós de } \\
\text { propranus }\end{array}$ & 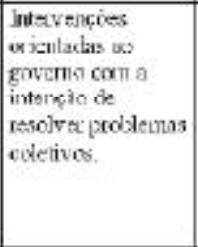 & 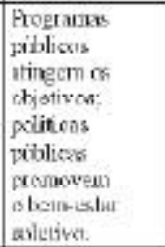 & 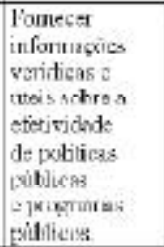 & Peratusx & 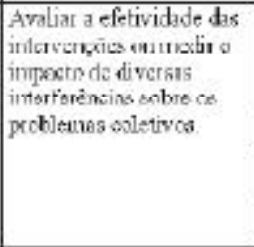 \\
\hline
\end{tabular}

Uma dimensão da variação consiste na imagem do funcionamento do governo. Em uma época na qual doutrinas de gestão pública encontram-se em evolução contínua e as auditorias de desempenho não foram ainda completamente institucionalizadas, seria surpreendente encontrar uma imagem única e definida para o funcionamento de governo que 
caracterize o conceito de auditoria de desempenho. Os seguidores da doutrina denominada learning organizations (organizações que aprendem) tentariam incorporar os MCIs referentes aos processos pelos quais o conjunto de crenças da organização é revisto à luz do feedback do sistema (Senge, 1990; Stacey, 1993), ao passo que os seguidores da doutrina do performance management (gerenciamento do desempenho) iriam buscar incorporar os MCIs que pudessem refletir a reação dos agentes governamentais ao defrontar-se com metas operacionais e incentivos estabelecidos de cima para baixo (Boyle, 1989). Partidários de diferentes linhas doutrinárias normalmente argumentam de forma a procurar agregar as idéias que postulam ao sentido central do conceito. As discussões sobre a auditoria de desempenho e sua prática tendem a ser encaminhadas de maneira distinta nos diferentes países. Com o intuito de facilitar o presente debate, é importante abstrair-se de questões de interesse meramente local.

Nas discussões no âmbito de grupos de profissionais que realizam auditoria de desempenho, um padrão de modelo mental é um esquema centrado no processo, semelhante àquele da cadeia de produção (Porter, 1985: 36). Nesse esquema, os insumos são transformados em produtos que, por sua vez, geram os impactos. Mais especificamente, o funcionamento do governo é caracterizado como um processo produtivo de transformação de insumos e relações causais, pelos quais os produtos influenciam o estado das coisas, cuja melhoria é normalmente considerada o principal objetivo das políticas públicas. Os processos de produção transformam insumos em produtos e os produtos exercem influência sobre os resultados. As ligações entre os insumos e os produtos, em particular, são percebidas como passíveis de manipulação pelos gerentes dos processos de produção, ao menos em médio e longo prazos.

Os modelos mentais de funcionamento de governo, subjacentes aos outros dois principais conceitos de revisão governamental ex-post, são bastante conhecidos. Para a auditoria tradicional, o principal modelo é o de máquina burocrática (Mintzberg, 1983: 163). Os sistemas nesse modelo operam na forma de processos de trabalho padronizados - mais especificamente estabelecendo, aplicando ou implementando critérios diferenciados por funções. Uma imagem característica do funcionamento do governo por trás do conceito de auditoria tradicional é aquela na qual os especialistas, situados na estrutura técnica, como os contadores, estabelecem políticas e procedimentos sancionados pelas categorias profissionais para uma organização específica. Os colaboradores individuais das linhas de produto são orientados, assim, a seguirem esses critérios sob a supervisão de seus superiores hierárquicos. O modelo cognitivo de funcionamento de governo, embutido no conceito de avaliação de programas, por sua vez, minimiza a importância do funcionamento interno das organizações 
governamentais e focaliza a influência do desenho e implementação do programa como um todo sobre condições sociais problemáticas. Portanto, utilizando uma metáfora da esfera da medicina, poder-se-ia dizer que os governos devem funcionar usando os produtos dos programas como "remédios" para o tratamento de condições sociais pouco saudáveis e inaceitáveis.

A imagem escolhida para o funcionamento do governo tem implicações óbvias sobre o que se considera o modelo ideal de operação. Conforme o modelo de máquina burocrática, uma organização que funciona bem é aquela cujos critérios de operação são apropriados, do ponto de vista profissional e organizacional, e cujos sistemas regulatórios mantêm as tarefas e as transações (e as pessoas que as executam) sob controle. Já na perspectiva da avaliação de programas, um programa efetivo é um tratamento que cura (ou pelo menos controla) o mal social, sem prejudicar a sociedade como um todo. Os programas dignos de mérito são aqueles que atingem os objetivos de determinada política pública ou, conforme alguns relatos, geram benefícios que excedem a soma dos custos dos recursos empregados e das consequiências adversas dos subprodutos (Moore, 1995). Por sua vez, as principais medidas de mérito embutidas no conceito de auditoria de desempenho são a economia, a eficiência e a efetividade. A economia geralmente significa a eliminação dos desperdícios de insumos; a eficiência refere-se à otimização dos processos de transformação de insumos em produtos; e a efetividade significa influenciar positivamente o impacto por meio da geração de produtos (Gray, Jenkins e Segsworth, 1993). A imagem de uma organização governamental eficiente está associada, neste caso, àquela na qual a atenção da administração está voltada para a otimização de processos produtivos flexíveis, bem como para a adaptação dos desenhos dos programas em função do feedback recebido e das mudanças nas prioridades e nos objetivos das políticas públicas.

O principal objetivo de um trabalho de revisão normalmente consiste em assegurar um nível satisfatório de funcionamento das organizações governamentais. O principal objetivo da auditoria tradicional é fazer que as unidades e os indivíduos sigam determinados critérios ou normas aplicáveis para realizar transações e desempenhar tarefas — resumidamente, o principal objetivo consiste em fazer uma accountability de regularidade (Light, 1993). A meta é impedir ou retificar procedimentos que representem desvios das normas legais, e.g., no controle financeiro ou na administração de ativos. Por outro lado, o principal objetivo das auditorias de desempenho pode ser expresso como accountability de desempenho. A idéia simples que está por trás desse argumento é que as organizações devem ser responsabilizadas pelos resultados de sua atuação mais do que pela sua forma de funcionamento. A idéia mais complexa é que, para 
alguns propósitos, é melhor focalizar a atenção da administração para a otimização de processos produtivos e do desenho dos programas. Uma estratégia apropriada para esse enfoque seria a de responsabilizar indivíduos e organizações pelo atendimento de padrões razoáveis de economia, eficiência e efetividade (a operacionalização dessa estratégia pode incluir a formalização de acordos entre um órgão e seu respectivo ministério, envolvendo a definição de várias metas). O objetivo da auditoria de desempenho, nesse sentido, é contribuir para a operacionalização de processos políticoadministrativos pelos quais a accountability de desempenho é estruturada, incentivada e controlada. ${ }^{6} \mathrm{Na}$ avaliação de programas, o principal objetivo é distinguir os impactos provocados pelos programas de forma a avaliar sua efetividade em atingir objetivos pré-definidos ou inferidos.

A modalidade de revisão governamental predominante difere entre os três tipos aqui analisados. A auditoria envolve a coleta de informações sobre as transações ou processos para determinar se eles estão em conformidade com as normas aplicáveis. A avaliação de programas convencionalmente envolve a execução e o desenho de estratégias de pesquisa para a realização de inferências descritivas válidas, confiáveis e isentas sobre condições agregadas, bem como de inferências causais sobre os impactos dos programas. A auditoria de desempenho algumas vezes envolve auditoria ou pesquisa, mas normalmente pode ser caracterizada como um processo de inspeção. A inspeção consiste no questionamento de qualquer tipo de procedimento, não apenas aqueles relativos à administração financeira. Uma inspeção pode tanto envolver a verificação da observância dos critérios aplicáveis como também o exercício direto de julgamento instrumental.

O papel do revisor/auditor pode ser deduzido pelos aspectos acima abordados. O papel do auditor público é examinar a informação apresentada pelos órgãos públicos e relatar eventuais desvios entre os critérios/ normas aplicáveis e as transações efetivamente realizadas ou os sistemas existentes. O papel do avaliador de programa é de conceber e desenvolver pesquisa que produza pareceres técnicos, com base em dados empíricos, sobre os impactos dos programas. Já o papel do auditor de desempenho é, em grande medida, o de avaliar aspectos selecionados dos programas e das organizações. Esses auditores normalmente avaliam esses aspectos com um enfoque mais pontual do que os revisores ao realizar uma típica avaliação de programas. Diferentemente dos auditores tradicionais, os auditores de desempenho podem julgar se os meios empregados nos processos produtivos estão alinhados com as metas estabelecidas ou se foram otimizados de forma a reduzir as limitações do programa.

Uma provável objeção a essa análise conceitual seria que ela deixa de especificar a independência da auditoria como atributo essencial da auditoria de desempenho. A principal razão para se adotar um conceito 
que não faz referência à questão da independência é que a relação entre órgãos centrais de auditoria e seu ambiente institucional varia bastante nos diferentes países. Alguns órgãos centrais de auditoria estão vinculados principalmente ao Poder Executivo (até mesmo fazendo parte dele), outros estão vinculados ao Legislativo e outros, ainda, são centros de poder independentes que se respaldam em leis e em coligações políticas entre o Executivo e o Legislativo. Ao introduzirmos o conceito de independência da auditoria no âmbito da definição de auditoria de desempenho, corremos o risco de menosprezar essas diferentes conformações, que são importantes para a análise aqui desenvolvida, conforme será visto a seguir.

Uma segunda objeção que se vislumbra é a de que a definição proposta para a avaliação de programas esteja ultrapassada. Apesar de inicialmente a avaliação de programas ter-se preocupado em pesquisar se os programas atingiam os objetivos ou se os tratamentos de políticas públicas eram eficientes na cura de males coletivos, essa área de atividade tem evoluído bastante (Hellstern, 1991). Pode até ser que hoje apenas uma minoria de profissionais da avaliação esteja de fato fazendo avaliação de programas. A posição adotada aqui é a de que o sentido central do conceito de avaliação de programas permanece sendo o clássico, e que, como demonstra a prática, os profissionais da avaliação estão cada vez mais engajados em trabalhos de auditoria de desempenho.

Uma terceira objeção seria quanto ao fato de que esse esquema conceitual tece uma caricatura da auditoria tradicional, considerando que a melhoria de eficiência seria, de fato, uma das metas permanentes da auditoria. Caso algumas entidades de auditoria tenham promovido a eficiência como principal meta operacional da auditoria tradicional, trata-se de uma questão empírica. Nessa hipótese, a atividade de revisão desenvolvida por essa instituição deveria ser classificada como auditoria de desempenho ou como uma forma híbrida.

Essa linha de raciocínio leva à conclusão de que a auditoria de desempenho, na realidade, não se trata de auditoria. A auditoria de desempenho é, de fato, avaliação: ela envolve a produção ou a revisão de instrumental de julgamento, como, por exemplo, sobre o nível de otimização dos processos produtivos e do desenho dos programas. A auditoria, por outro lado, é uma forma de verificação (Chelimsky, 1985): ela envolve a comparação de critérios usualmente aceitos com as transações realmente efetivadas e os sistemas implementados. A aplicação do instrumental de julgamento pode ser feita de forma a parecer uma verificação se a entidade que estiver realizando a auditoria de desempenho se estrutura como uma organização do tipo máquina burocrática e padroniza o trabalho da auditoria de desempenho. Nesse caso, os critérios aplicados pelos auditores de desempenho seriam conceitualmente regras de ouro (rules of thumb) e 
não normas compulsórias chanceladas por profissionais da área, tais como as regras para efetuar transações ou para elaborar relatórios financeiros.

A expressão auditoria de desempenho é, portanto, um rótulo impreciso para o conceito nela embutido. Uma vez rotulada com esse nome, deve-se insistir que nada mudará o fato de que a denominação utilizada para o conceito inclui a palavra auditoria. A reflexão sobre a auditoria de desempenho, contudo, não deve ser guiada por conotações da palavra auditoria, mas sim pelo sentido central do conceito como caracterizado por modelos cognitivos mentais inter-relacionados como aqueles identificados no Quadro 1. Isso implica, mais especificamente, que a auditoria de desempenho - como um tipo - não se encontra mais próxima da auditoria tradicional do que da avaliação de programa. Colocado de uma outra forma, a auditoria de desempenho não consiste em categoria subordinada, juntamente com a auditoria tradicional, à categoria mais ampla denominada auditoria.

\section{Fonte e qualidade dos dados}

Como preparação para recente simpósio sobre auditoria de desempenho, o Serviço de Administração Pública da OCDE consultou os órgãos centrais de auditoria dos países-membros sobre os tipos de revisão governamental que eles realizavam, com ênfase naqueles que poderiam ser classificados como auditorias de desempenho. As respostas dos órgãos de auditoria de 13 países-membros foram resumidas no documento oficial do simpósio elaborado pelo secretário (Shand e Anand, 1996: apêndice). Este tópico irá utilizar essa fonte de informação para fins de análise empírica. ${ }^{7}$

Dentre os 13 países-membros da OCDE que encaminharam respostas, 12 realizam tipos de revisão governamental que poderiam ser classificados como auditoria de desempenho. Alguma forma de auditoria de desempenho é praticada nos países de língua inglesa da Europa, Oceania e América do Norte; em três países escandinavos; e na França, Alemanha e Holanda. Com base no relatório encaminhado à OCDE, o Tribunal de Contas de Portugal aparentemente não realiza auditorias de desempenho (apesar de ter a competência legal para fazê-lo). Considerando o enfoque dado ao pedido de informações da OCDE, a ausência de manifestação por parte de alguns países-membros pode indicar que a auditoria de desempenho não é realizada pelos órgãos centrais de auditoria na Dinamarca, Grécia, Itália, Japão, República da Coréia, México, Espanha e Turquia. Sem maiores informações sobre esses países, a tentativa de abordar a questão da presença ou ausência da auditoria de desempenho nos portfolios das atividades de revisão dos órgãos centrais de auditoria seria um esforço especulativo estéril. 
Caberia observar que, contudo, se a falta de respostas for atribuída à não-realização de auditoria de desempenho, essa informação seria amplamente consistente com outros padrões na administração pública. Doutrinas de administração pública voltadas para o desempenho têm conquistado espaços significativos nos países em que os órgãos centrais de auditoria procuram realizar trabalhos de auditoria de desempenho. A França e a Alemanha são os únicos países em que as burocracias nacionais são cépticas quanto às doutrinas administrativas voltadas ao desempenho, contudo, os órgãos centrais de auditoria ainda assim parecem realizar auditoria de desempenho. ${ }^{8}$ Por outro lado, nenhum dos países que se absteve de responder à pesquisa da OCDE é conhecido como solo fértil para as idéias da nova gestão pública (com exceção da Dinamarca). ${ }^{9}$

\section{Variações encontradas na classificação das auditorias de desempenho}

Considerando que apenas um país consultado respondeu que não realiza auditoria de desempenho, seria indicada uma abordagem de pesquisa comparada que verifique as variações entre os casos estudados. Os relatórios dos países sugerem que alguns órgãos de auditoria central possuem linhas de produtos de auditoria de desempenho limitadas, enquanto em outros elas são bastante diversificadas. Um passo preliminar para se identificar as variações observadas entre os casos relatados seria o desenvolvimento de um esquema de classificação das auditorias de desempenho. Elas parecem variar conforme quatro dimensões-chave: unidade de análise, modalidade de revisão, abrangência da avaliação e foco do trabalho. Com base nas informações colhidas no simpósio da OCDE e em outras fontes, sete tipos de auditoria de desempenho podem ser identificados e caracterizados nos seguintes termos (Quadro 2).

\section{Auditorias de eficiência e de efetividade de programa}

A auditoria de eficiência examina as funções organizacionais, os processos e os elementos de programa para avaliar se os insumos estão sendo transformados em produtos de forma otimizada, especialmente no que concerne aos custos. Estas auditorias usualmente envolvem múltiplos auditados, já que os processos normalmente perpassam toda a organização devido à centralização funcional na esfera do governo (e.g., em áreas 
administrativas como finanças, pessoal, compras, estoques, e tecnologia da informação), à descentralização administrativa e à contração direta do setor privado.

\section{Quadro 2: Tipos de auditoria de desempenho}

\begin{tabular}{|c|c|c|c|c|}
\hline Tpo & Linidade de análige & $\begin{array}{l}\text { Modalidade } \\
\text { de nevigasc }\end{array}$ & $\begin{array}{l}\text { Abrangência } \\
\text { da svaliacion }\end{array}$ & Foro do traballo \\
\hline $\begin{array}{l}\text { Auditoria de } \\
\text { etiçişoçis }\end{array}$ & $\begin{array}{l}\text { Funglo } \\
\text { orpsuiraciongl, } \\
\text { procesen ou elinento } \\
\text { de prog ama }\end{array}$ & lnspeçio & $\begin{array}{l}\text { Aspcctos de oxiacois } \\
\text { govenumim encais on de } \\
\text { Terceiros }\end{array}$ & 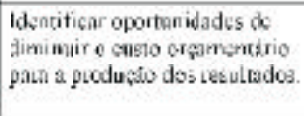 \\
\hline $\begin{array}{l}\text { Auditoria de } \\
\text { etcrividade de } \\
\text { prcemama }\end{array}$ & 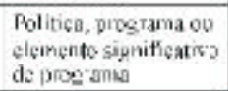 & lnsucçấ & 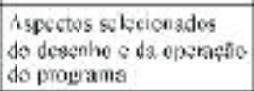 & 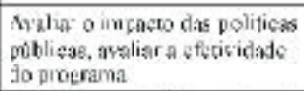 \\
\hline 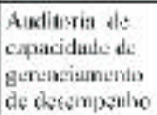 & Olganicacaso & Tuspcçaิ & 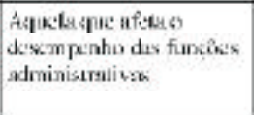 & 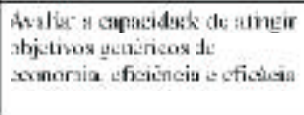 \\
\hline $\begin{array}{l}\text { Auditoria de } \\
\text { infonnackexd: } \\
\text { dusconpenta }\end{array}$ & Diganicacto & Audicoria & 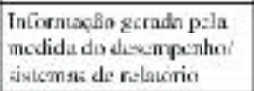 & 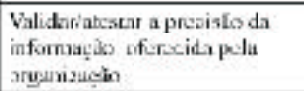 \\
\hline $\begin{array}{l}\text { Aralingàn } \\
\text { de nisoo }\end{array}$ & Progrtaina & Inspieà & $\begin{array}{l}\text { Jodos ce aspectos dc } \\
\text { dzscnlm o da oporaysin do } \\
\text { frongrama }\end{array}$ & 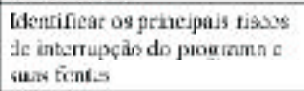 \\
\hline $\begin{array}{l}\text { Revisía da } \\
\text { ctellot prícica } \\
\text { de gestaic }\end{array}$ & $\begin{array}{l}\text { L'm serar ine'm } \\
\text { jrovessa genérico au } \\
\text { funvajo comur: }\end{array}$ & Pearinisa & 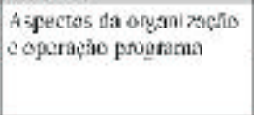 & 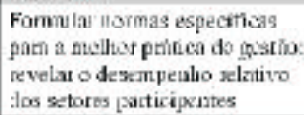 \\
\hline 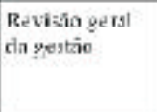 & Drẹtani miesan & 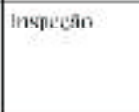 & 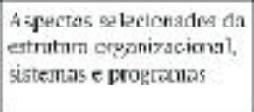 & 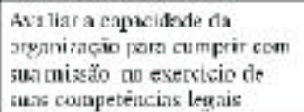 \\
\hline
\end{tabular}

A auditoria de efetividade de programa examina o impacto provocado pelos programas sobre os resultados finais. As conclusões às quais se chega são, portanto, semelhantes àquelas da avaliação de programas, mas a utilização de métodos de pesquisa de ciências sociais para se alcançar tais conclusões é mais limitada. Além disso, as auditorias de efetividade de programa preocupam-se mais com a avaliação de elementos pontuais do programa do que com avaliação de programa, na qual o objeto da avaliação consiste no programa como um todo. Um caso especial de auditoria de efetividade de programa é a avaliação da qualidade de serviço. ${ }^{10}$

\section{Auditoria de capacidade de gerenciamento de desempenho}

A auditoria de capacidade de gerenciamento de desempenho busca avaliar se o auditado tem capacidade para gerenciar processos e programas de forma eficiente e efetiva. ${ }^{11} \mathrm{O}$ objeto da avaliação — capacidade de gerenciamento do desempenho - não é claramente observável. ${ }^{12}$ 
As inferências sobre a capacidade são sempre obtidas ao se observar a estrutura e os procedimentos de determinado órgão. Essa modalidade de auditoria pode avaliar se um auditado implementou um processo orçamentário orientado para resultados, conforme determinação dos órgãos centrais; ou pode ainda examinar se um auditado realizou avaliações rotineiras da efetividade de seus próprios programas ou se desenvolveu um sistema de gerenciamento de desempenho adequado, contemplando os objetivos organizacionais, os objetivos em nível de unidade, indicadores de desempenho específicos, rotinas de mensuração de indicadores de desempenho, sistemas de informação gerencial, bem como procedimentos para a avaliação de desempenho setorial e individual. A formação de juízo de valor sobre a capacidade de desempenho gerencial é extremamente afetada pela filosofia de gestão pública que prevalece no órgão auditor, em particular, ou no governo nacional. Como discutido anteriormente, cada corrente doutrinária - como gestão responsável, gestão da qualidade total e doutrina das organizações que aprendem — tem sua visão particular sobre quais configurações ou práticas permitem às organizações públicas serem gerenciadas de forma orientada para o desempenho.

\section{Outros tipos de auditoria de desempenho}

As auditorias de informações de desempenho verificam a precisão de informações não-financeiras geradas pelas próprias entidades examinadas. O órgão revisor não avalia a economia, eficiência ou efetividade de uma organização ou programa, mas sim formula um parecer sobre a veracidade das informações de desempenho fornecidas às instâncias superiores. Esse tipo de auditoria de desempenho facilita um processo de padronização da avaliação organizacional realizada pelos usuários das informações de desempenho auditadas, como altos funcionários da área orçamentária e formuladores de políticas públicas. Como a verificação da informação relatada é a principal função desse tipo de auditoria, a modalidade de revisão predominante é a auditoria e não a inspeção. As auditorias de informações de desempenho não representam, portanto, um caso típico do conceito de auditoria de desempenho.

As revisões da melhor prática de gestão identificam em que um dado tipo de função está sendo desempenhada de forma excepcional e procuram discernir as razões daquele sucesso relativo. $\mathrm{O}$ objeto típico dessa avaliação é uma função desenvolvida em um grande número de organizações, como, por exemplo, radiologia no setor hospitalar, ou um processo genérico, como a aquisição de tecnologia da informação. O processo de coleta e análise de dados, por meio de critérios de avaliação 
pré-estabelecidos, orienta-se por métodos de pesquisa em ciência social.

Esses métodos são utilizados presumivelmente para identificar os fatores, como métodos e procedimentos, responsáveis pelos resultados positivos. Diferentemente do caso típico de auditoria de desempenho, a principal modalidade de revisão envolvida nos estudos da melhor prática de gestão é a pesquisa. A utilização dada aos resultados dos estudos de melhor prática depende da estratégia organizacional do órgão central de auditoria. A UK Audit Comission for England and Wales (Comissão de Auditoria do Reino Unido para a Inglaterra e País de Gales) — bastante conhecida por essa modalidade de estudo — publica e distribui seus relatórios. Além disso, a função de planejamento de auditoria, seguindo o modelo burocrático, traduz seus achados em critérios a serem utilizados por auditores na realização de auditorias de programa e de efetividade (conhecidas, no Reino Unido, como auditorias de value-for-money). ${ }^{13}$

As avaliações de risco indicam aos formuladores de políticas públicas e gerentes do alto escalão os graves problemas que podem advir caso um programa seja mantido na mesma linha da operação. As avaliações de risco são mais orientadas para o futuro do que a maioria das auditorias de desempenho, são, entretanto, no aspecto conceitual, revisões ex-post, baseadas em informações sobre programas já em operação. Esse tipo de auditoria de desempenho diferencia-se das auditorias de efetividade de programa uma vez que não necessita posicionar-se quanto à efetividade do programa. O papel desse tipo de auditoria é o de identificar formas pelas quais os programas existentes podem sofrer interrupção no futuro e alertar os políticos e os gerentes quanto a essa possibilidade. ${ }^{14}$

As revisões gerais de gestão avaliam organizações em vez de programas. Quando essas revisões vão além das auditorias de desempenho da capacidade gerencial, elas geralmente buscam as causas significativas para problemas ou sucessos persistentes na esfera do desempenho dentro de uma gama de atividades de um programa. As revisões gerais de gestão conduzidas pelo $G A O$ no Ministério da Habitação e Desenvolvimento Urbano são um exemplo. ${ }^{15}$

\section{Explicando as freqüências}

Esses conceitos foram utilizados para tabular informações sobre a realização de auditorias de desempenho. ${ }^{16}$ Três tipos de auditoria de desempenho são amplamente disseminados. As auditorias de eficiência são as mais freqüentes, seguidas pelas auditorias de capacidade de gerenciamento de desempenho e pelas auditorias de efetividade de programa. As auditorias de informação de desempenho são realizadas por um número mais reduzido de órgãos de auditoria, mas estão tornando-se 
cada vez mais freqüentes. Assim, as auditorias de eficiência são desenvolvidas por quase todos os órgãos centrais de auditoria, as auditorias de capacidade de gerenciamento do desempenho por dois terços, as auditorias de efetividade de programa por cerca de metade e as auditorias de informações de desempenho por cerca de um quarto dessas instituições, conforme mostra o Quadro 3.

Quadro 3: Principais tipos de auditoria de desempenho por país

\begin{tabular}{|c|c|c|c|c|}
\hline & $\begin{array}{c}\text { Auditoria } \\
\text { de cficiéncin }\end{array}$ & $\begin{array}{l}\text { At,ditoria de } \\
\text { efctividade de } \\
\text { proparama. }\end{array}$ & $\begin{array}{l}\text { Auditoria de } \\
\text { cnpacidado do } \\
\text { gerenciamento } \\
\text { do descmpenhó }\end{array}$ & $\begin{array}{l}\text { Auditonia de } \\
\text { informaçōes } \\
\text { de desempenho }\end{array}$ \\
\hline Austrilia & $\checkmark$ & 1 & $r$ & \\
\hline Canzdá & $\checkmark$ & & $\checkmark$ & \\
\hline Finląndị & $r$ & & $\checkmark$ & $\checkmark$ \\
\hline Fìnça & $\checkmark$ & 4 & & \\
\hline Nlemanha & $\checkmark$ & $\checkmark$ & $\checkmark$ & \\
\hline Iriąnda & $\checkmark$ & & $\checkmark$ & \\
\hline Holanda & $\gamma$ & $\gamma$ & 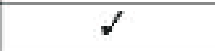 & \\
\hline Nova 7eländia & $\checkmark$ & & & $\checkmark$ \\
\hline Noruega & $\checkmark$ & & $\checkmark$ & \\
\hline \multicolumn{5}{|l|}{ P'urlugal } \\
\hline Snciata & $\checkmark$ & 4 & $\checkmark$ & $\checkmark$ \\
\hline Reino Unido & $\checkmark$ & $\checkmark$ & & \\
\hline Estadus Lindos & $\gamma$ & $\gamma$ & $\checkmark$ & \\
\hline
\end{tabular}

Esse padrão de freqüência observado guarda alguma consistência com as teorias mais comuns de comportamento burocrático que enfatizam a resistência às mudanças institucionais e a preferência por autonomia organizacional. As auditorias de eficiência não implicam uma reformulação radical da missão, do papel e da estratégia organizacional dos órgãos de auditoria. A eficiência tem sido considerada um valor fundamental em todos os órgãos de auditoria, com exceção daqueles mais legalistas. ${ }^{17}$ Existe o entendimento de que as avaliações de eficiência não constituem ou implicam uma avaliação de política governamental — uma crença que tende a garantir a autonomia institucional. Os órgãos de auditoria que realizam auditoria de eficiência podem ainda recrutar seus técnicos dentro do mesmo grupo limitado de profissionais; estruturar as tarefas dos auditores de forma semelhante; e manter normas similares de relacionamento profissional com os órgãos auditados. Mesmo se as rotinas se distanciarem um pouco do modelo tradicional de trabalho, o corpo técnico pode, ainda assim, sentir-se seguro, pois a missão e o papel do órgão de auditoria permanecem estáveis. 
A ampliação da missão do órgão fiscalizador está implícita, em certa medida, nas auditorias de capacidade de gerenciamento do desempenho. Com efeito, nesse caso, a missão dos órgãos de auditoria passa a incorporar, de forma incisiva, o conceito da boa gestão definida de forma mais abrangente, não se limitando simplesmente à boa prática administrativa definida de forma específica. Mas a auditoria da capacidade de gerenciamento do desempenho não afeta necessariamente o papel tradicional do órgão de auditoria. ${ }^{18}$ Dentro da dicotomia política/administração, a capacidade de gestão do desempenho é conceitualmente uma questão administrativa, já que diz respeito à implementação de políticas e não ao mérito ou efetividade dessas políticas. Além disso, na prática, as conclusões da auditoria de capacidade de gerenciamento do desempenho não são tão politicamente sensíveis, já que não se relacionam com a efetividade dos programas de política econômica, social, ambiental, de defesa ou cultural. Assim, os riscos para a autonomia organizacional são moderados, a única ameaça consiste na possibilidade de a organização não ser vista como tendo a competência técnica apropriada para desenvolver esse tipo de auditoria.

A expansão das linhas de produto para incluir as auditorias de efetividade de programa, por outro lado, amplia a missão, o papel e a estratégia organizacional dos órgãos de auditoria de orientação tradicional. ${ }^{19}$ Nesse caso, a missão é concebida em termos mais amplos e abstratos. Surge a demanda pela contratação de empregados dentro de um grupo mais diversificado de profissionais, incluindo aqueles da área de ciência de gestão e de avaliação governamental, bem como pelo desenvolvimento de novas rotinas para vários processos de trabalho. Ademais, o que é mais importante, a ênfase no aspecto administrativo da dicotomia política/administração afeta o papel tradicional da entidade. Como os resultados das auditorias de efetividade de programa tendem a ser mais suscetíveis a questionamentos de natureza política, o órgão de auditoria corre assim o risco de ser envolvido em questões políticas que podem ameaçar sua autonomia organizacional.

As teorias da resistência burocrática à mudança e da preferência pela autonomia são, portanto, consistentes com a freqüência relativa das auditorias de eficiência, de capacidade de gerenciamento de desempenho e de efetividade de programa. Esses fatores, contudo, não explicam por que as auditorias de informações de desempenho são realizadas por relativamente poucos órgãos de auditoria. Esse tipo de auditoria de desempenho envolve uma discreta ampliação da missão, mudanças marginais na estratégia organizacional e nenhuma mudança no papel institucional. A explicação parece estar no fato de que as auditorias de informações de desempenho são realizadas nos países em que os governos assumiram compromissos doutrinários com uma administração 
pública orientada a resultados e encontram-se no processo de construção de sistemas e procedimentos de revisão e elaboração orçamentária fundamentados nessa idéia (Suécia). Assim, o ambiente organizacional parece oferecer um fator geral de explicação para a freqüência dos diferentes tipos de auditoria de desempenho.

\section{Explicando as variações}

O Quadro 3 oferece informações sobre o resultado das decisões que concernem à composição das linhas de produto em 13 países. Observase que uma linha de produto mais extensa de auditoria de desempenho incluindo as mais politicamente sensíveis auditorias de efetividade de programa - ocorre em cinco países: Austrália, Alemanha, Holanda, Suécia e EUA. Partilham esses países de propriedades comuns às quais pode-se atribuir a ocorrência dos resultados mais freqüentes?

Nesse ponto, faz-se necessário recorrer à teoria para identificar essas propriedades. A teoria do gerenciamento estratégico presta-se a essa tarefa, já que lida com a forma pela qual a organização se posiciona dentro de seu ramo de atividade industrial e do mercado de seu produto. As variantes dessa teoria para o setor público lidam, analogamente, com a forma pela qual as competências de uma entidade, sejam elas estatutárias ou informais, são criadas e modificadas (Selznick, 1957; Derthick, 1979; Wilson, 1989; Mashaw e Harfst, 1990). Sobre as abordagens sistêmicas da teoria de gerenciamento estratégico, entende-se que as decisões tomadas pelo Executivo não só levam em consideração as variáveis estruturais como são fortemente delimitadas por elas. ${ }^{20}$ No caso de entidades públicas, essas variáveis estruturais incluem padrões de relacionamento entre Executivo e Legislativo, o regime político, o status constitucional da organização em análise, as relações com clientes e eleitores, as preferências políticas e doutrinárias de grupos de interesse externos e internos, o posicionamento mercado/indústria, bem como a atuação de outras entidades na mesma área organizacional (Weaver e Rockman, 1993; Moore, 1995).

Entre os cinco casos que apresentam o mesmo resultado, vários possuem um padrão de relacionamento Legislativo/Executivo parlamentarista e apenas um se enquadra no modelo de separação de poderes. Ao menos nesse nível de classificação geral, reina a diversidade. Não existe também uma uniformidade aparente no status constitucional dos órgãos de auditoria. Na Suécia, o Órgão Central de Auditoria $(R R V)$ vincula-se constitucionalmente ao Executivo. Nos Estados Unidos, o GAO integra o poder Legislativo. $\mathrm{Na}$ Austrália, Alemanha e Holanda, o órgão central de auditoria posiciona-se, em nível constitucional, fora da esfera 
do Legislativo e do Executivo. Assim, se o padrão de relacionamento

Executivo/Legislativo influencia os resultados, isso não ocorre de maneira tão simples ou direta. ${ }^{21}$

O padrão de relacionamento com os principais clientes também não apresenta uniformidade. Em razão de seu posicionamento dentro do sistema governamental, a EFS sueca tem como principal cliente o Ministério das Finanças, ao qual essa entidade está administrativamente vinculada, ao passo que os clientes principais do $G A O$ são as comissões e as subcomissões parlamentares do congresso americano. O Tribunal de Contas da Alemanha aparentemente tem clientes tanto no Poder Legislativo quanto no Executivo, sendo que o maior fluxo de troca de informações e apoio ocorre com a comissão de orçamento da câmara baixa do Parlamento e sua subcomissão de contas públicas, de natureza não-partidária (Zavelberg, 1995). Esses países têm em comum o fato de que seus órgãos centrais de auditoria possuem clientes poderosos, seja na esfera política ou administrativa.

Nos casos da Alemanha e Estados Unidos, o relacionamento Executivo/Legislativo favorece uma extensa linha de produtos de auditoria de desempenho. Em nenhum desses casos os processos legislativos, incluindo a alocação de recursos orçamentários, são dominados pelo Executivo (Dahl, 1981: 127; Paterson e Southern, 1991: 122). O fato de o órgão central de auditoria ser considerado parte do Poder Legislativo ou independente de instituições políticas parece não ter maiores consequiências; tanto o GAO como as EFS alemã estabeleceram relacionamentos, em nível de cliente, não apenas com órgãos do Legislativo relacionados com a probidade e eficiência, mas também com unidades que lidam com temas politicamente relevantes, como a Comissão de Orçamento do Bundestag (Parlamento alemão). ${ }^{22}$ Os clientes desses órgãos de auditoria não têm maiores problemas em desafiar a dicotomia política/administração. Se essas EFS quiserem efetivamente atender a esses clientes poderosos, terão naturalmente que fazer dessa dicotomia uma construção mental menos importante para a sua identidade profissional e organizacional. Assim, essa forma particular de relacionamento com o cliente, condicionada pelo padrão geral de relacionamento Executivo/Legislativo, parece ser suficiente para superar as pressões sobre a extensão do papel institucional das EFS, advindas da realização de auditorias de efetividade de programa.

Em certa medida, o caso da EFS da Suécia assemelha-se à situação dos EUA e da Alemanha, a despeito do maior poder exercido pelo Executivo sobre o Legislativo daquele país. O domínio do Executivo sueco sobre o Legislativo explica por que o importante órgão central de auditoria está situado no âmbito do Executivo. Esse posicionamento, portanto, enseja um relacionamento de cliente com o Ministério das Finanças. Os funcionários da área de orçamento e o governo que eles servem, como as 
comissões legislativas da Alemanha e dos EUA, aparentemente não se preocupam com a dicotomia política/administração. A EFS da Suécia parece seguir o mesmo caminho.

Será que o padrão de relacionamento entre fatores explica os resultados nos casos em que a linha de produtos é mais limitada? Esse parece ser o caso da Nova Zelândia, onde as auditorias de efetividade de programa não são realizadas pelo órgão de auditoria (Office of the Auditor General - OAG, Nova Zelândia). O sistema governamental da Nova Zelândia é dominado pelo Executivo, e a EFS está constitucionalmente vinculada ao Parlamento. Os governos aparentemente não vêem com bons olhos o escrutínio parlamentar do tipo proporcionado pelas auditorias de efetividade de programa - e eles têm o poder de fazer valer seus interesses. A situação do Canadá é semelhante. O independente Gabinete do Auditor-Geral não possui mandato legal para realizar auditorias de efetividade. Isso se deve ao domínio do Executivo sobre o Parlamento. Na condição de órgão independente, a EFS do Canadá se mostra bastante cuidadosa em não ultrapassar esse limite legal.

No que tange ao relacionamento Executivo/Legislativo, a situação do Reino Unido não guarda consistência com esse padrão. O NAO é formalmente um órgão independente, cuja autoridade máxima é um funcionário do Parlamento. O seu cliente mais importante é a Public Accounts Committee — PAC (Comissão de Contas Públicas do Parlamento) em um regime no qual normalmente há forte relação de domínio do Executivo sobre o Legislativo. Mesmo assim, o NAO realiza auditorias de efetividade de programa. Na realidade, esse caso, aparentemente discrepante, é mais consistente com o padrão mencionado do que parece à primeira vista. A principal razão consiste no fato de que as auditorias de efetividade de programa, de certa forma, iludem o olhar do observador. Essas auditorias não devem questionar o mérito de políticas públicas, exigência que se coaduna com a competência legal do cliente do $N A O$ na esfera legislativa, a Comissão de Contas Públicas. O mandato legal para a realização de auditorias de efetividade de programa é limitado pela imposição de condições que são mais diretamente relacionadas com aspectos operacionais do que a temas que afetem a dicotomia política/administração. Dentre essas condições, encontra-se um conjunto de normas de procedimento para o planejamento de auditoria e elaboração de relatórios. Esse conjunto de normas prevê que o $N A O$ obtenha a concordância prévia dos ministérios com termos de referência que estabelecem a abrangência do estudo e, na outra ponta do processo, com o conteúdo do relatório final.

Apesar de os órgãos auditados poderem impedir a publicação dos relatórios das auditorias de efetividade de programa (assim como as de eficiência), o $N A O$ reserva-se no direito de relatar seus achados à Comissão de Contas Públicas em caráter reservado. Essa ação pode resultar em 
audiências abertas nas quais os membros da Comissão tomam depoimentos do ministro ou de outros funcionários do governo. ${ }^{23}$ Desprezando o equilíbrio de forças entre os poderes, as normas de procedimentos e as condições para a realização das auditorias conferem ao Executivo uma influência atípica sobre os termos de referência e sobre a divulgação das observações das auditorias de efetividade de programa. As características desse tipo de auditoria no Reino Unido, cujos relatórios são adaptados e possivelmente amenizados, fazem que os resultados das auditorias de efetividade de programa naquele país pareçam ser menos diferentes daqueles observados na Nova Zelândia e no Canadá. Considerando que os sistemas de governo nesses países são semelhantes, essa análise mais detalhada da situação no Reino Unido tende a confirmar (com nuances) o quadro explicativo aqui desenvolvido que emerge da análise comparativa de variações observadas. ${ }^{24}$

\section{Questões estratégicas de implementação}

A questão que se impõe aos órgãos de auditoria que realizam auditorias de desempenho é definir como devem avaliar as organizações e os programas, e não se devem fazê-lo. As avaliações conduzidas na modalidade auditoria consistem em resultados de processos consecutivos da organização, intencionalmente destacados, que podem ser classificados como: processos de definição e processos de aplicação de critérios. A definição de critérios é o processo de estabelecer regras de ouro que se aplicam a amplas categorias de organizações, funções ou programas. A aplicação de critérios consiste no processo de comparação de aspectos de organizações, funções ou programas específicos com as normas geralmente aceitas. A tarefa dos responsáveis pela definição de critérios consiste em formular diretrizes instrumentais para uma ampla categoria de casos. A tarefa dos encarregados da aplicação desses critérios é, por sua vez, determinar se um caso particular guarda conformidade com as normas gerais pré-definidas. A partir da observação da conformidade ou discrepância de determinado procedimento com as normas gerais, o órgão de auditoria faz uma inferência para chegar a um juízo de valor. Contudo, nenhum agente individual está autorizado a determinar quais seriam os procedimentos avaliados ou a definir as normas gerais.

Outras modalidades de avaliação envolvem a flexibilização de várias características determinantes da modalidade auditoria. Primeiramente, a abrangência dos critérios pode ser mais limitada. Os critérios, por exemplo, podem ser mais específicos, derivados dos objetivos dos programas ou das organizações. Os critérios intencionalmente definidos para ultrapassar 
o nível de desempenho observado de uma organização têm uma abrangência

igualmente limitada. Em segundo lugar, os critérios podem não ser de fato regras de ouro, mas sim consistir em uma função ou critério objetivo (como custo de minimização) ou em um procedimento para calcular os valores de variáveis relevantes (como os custos fixos e outras formas de desenvolver a mesma função). As revisões com enfoque na eficiência (Metcalfe e Richards, 1990) sempre empregam essas normas de procedimento genéricas em vez de "regras de ouro" (rules of thumb). Finalmente, os responsáveis pela aplicação dos critérios podem ter o poder discricionário não apenas de relevar algumas normas gerais, mas também de definir quais delas se aplicam ao caso concreto. Essas três formas de desvio da modalidade auditoria permitem a adaptação dos julgamentos avaliativos às particularidades de cada caso.

As diferenças entre a auditoria e outras modalidades de avaliação podem ser analisadas como diferenças entre processos decisórios fundamentados em "regras de ouro" (rules of thumb) e aqueles específicos para cada caso - uma diferenciação usual na teoria administrativa (Mashaw, 1983; Hood, 1986; Schauer, 1991). Um processo decisório governado por "regras de ouro" normalmente consegue restringir o exercício do poder discricionário com sucesso, mas ao custo de comprometer a otimização dos resultados (Schauer, 1991: 100-102). Isso se deve à tensão entre o particular e o geral: as normas podem ser apropriadas a toda uma categoria de organizações, mas a aplicação de regras pode redundar em decisões piores do que aquelas obtidas caso o conhecimento por trás da norma (ou, de forma equivalente, a justificativa por trás da regra) fosse empregado ao se lidar com um caso particular. Uma única vantagem do processo decisório orientado por regras consiste na internalização de controles: como ninguém tem o poder de definir os critérios e de aplicá-los ao mesmo tempo, o poder, em nível individual, é minimizado (Schauer, 1991: 158-162). A organização pode alegar que suas decisões, nesse caso, seus pareceres de auditoria, têm como atributos a consistência e a objetividade. Em suma, a redução do nível de otimização das decisões deve ser compensada por uma reputação de objetividade. Assim, não existe uma modalidade ideal de operação para se realizar as auditorias de desempenho.

Doutrinas de gestão pública podem influenciar a compensação desses valores. Algumas doutrinas de gestão pública ressaltam as conseqüências adversas de se adotar critérios do tipo fundamentado em regras, que se prestam a abarcar amplas classes de situações; ao mesmo tempo, essas teorias advogam que grandes benefícios podem ser obtidos ao permitir que funcionários envolvidos diretamente nas atividades empreguem seu conhecimento técnico, sabedoria gerencial e valores orientados a resultados de forma sensata no caso concreto. A aceitação 
da doutrina "pós-burocrática" (Barzelay, 1992) ou a da "nova gestão pública" (Hood e Jackson, 1991) fragiliza a opção pela avaliação do tipo padrão e fortalece a causa da auditoria de desempenho feita sob medida.

Tais doutrinas, quando aplicadas à auditoria de desempenho, podem ser criticadas por não considerarem as conseqüências negativas de expor a EFS à acusação de que suas avaliações são questionáveis e arbitrárias. ${ }^{25}$ Para se fazer uma análise adequada da escolha da modalidade de operação, deve-se levar em consideração os riscos que esses desafios podem acarretar aos órgãos centrais de auditoria. Nesse ponto, a análise da implementação das decisões aproxima-se da análise política da auditoria de desempenho desenvolvida no item anterior.

Um órgão de auditoria está menos sujeito a esse tipo de crítica quando serve a um cliente poderoso do Legislativo ou Executivo ou se conseguiu construir alianças de apoio eficazes. Enquanto os clientes ou os aliados não oferecerem resistência ao exercício da atividade de julgamento em uma modalidade relativamente específica, o órgão de auditoria pode estar protegido de ameaças mais sérias. A opção pela auditoria como uma modalidade de avaliação é, assim, menos problemática nessas circunstâncias do que quando uma EFS está preocupada, com toda propriedade, em salvaguardar a legitimidade das conclusões da auditoria de desempenho bem como acredita que a realização de auditorias seja essencial para demonstrar que suas conclusões são consistentes e objetivas. ${ }^{26}$

Se um órgão de auditoria assume o compromisso estratégico de adotar modalidades de avaliação de natureza específica, o dilema estratégico está resolvido, mas a tensão subjacente às duas modalidades não desaparece. Os valores de legitimação sobre os quais esses órgãos compostos por agentes públicos detentores de cargos não-eletivos se fundamentam são a imparcialidade, a capacidade técnica e o desempenho. Para garantir sua legitimidade, a alta administração desses órgãos precisa incorporar, em suas organizações, elementos estruturais que demonstrem que tais valores permanecem válidos independentemente de o processo de auditoria ser do tipo padronizado ou fundamentado em regras (Meyer e Rowan, 1977). A Corte de Contas da França demonstra sua capacidade técnica ao recrutar funcionários entre os melhores alunos da Ecole Nationale d'Administration (Escola Nacional de Administração). O GAO, por sua vez, demonstra sua capacidade técnica por meio de um processo aparentemente rigoroso de controle de qualidade, no qual diferentes funcionários, como, por exemplo, o economista-chefe, revisam as minutas de relatório de auditoria de desempenho antes de sua liberação para divulgação (Napa, 1994). O NAO mostra sua imparcialidade ao enfatizar o seu relacionamento, em nível de cliente, com a Comissão de Contas Públicas, de caráter não-partidário. 
Em suma, existe um sistema de compensações (trade-off), de natureza técnica, entre a modalidade auditoria de desempenho padronizada e aquela feita sob medida. As doutrinas de gestão pública podem influenciar visões sobre as vantagens técnicas relativas das diferentes modalidades, sendo que as idéias da Nova Gestão Pública favorecem aquelas de natureza mais específica, do tipo feita sob medida. Entretanto, a legitimidade da instituição é outro aspecto a ser considerado. Imparcialidade, capacidade técnica e profissionalismo são valores de legitimação universais para todos os órgãos de auditoria. As pressões institucionais para se demonstrar que tais valores são observados internamente não levam necessariamente à adoção da modalidade auditoria, na auditoria de desempenho. A escolha depende das preferências dos clientes dos órgãos de auditoria, da tolerância dos que conduzem os trabalhos de auditoria para com o envolvimento institucional em controvérsias políticas e da habilidade para se adotar estratégias compensatórias para ocupar vácuos de legitimidade.

\section{Accountability e melhoria do desempenho}

A julgar pelas respostas encaminhadas por alguns responsáveis pela execução da atividade de auditoria, um segundo tema estratégico seria a conveniência de se gerenciar o processo de auditoria de desempenho de forma a contribuir diretamente para a melhoria do desempenho do órgão auditado. A alternativa usual seria limitar-se a fortalecer os laços de accountability entre os dirigentes governamentais e seus agentes burocráticos (Stewart, 1984), dando ênfase aos resultados e não aos insumos e procedimentos. A política organizacional nessa matéria tende a afetar o procedimento e estilo dos trabalhos em cada estágio do processo de auditoria de desempenho, incluindo o planejamento, a execução e a elaboração do relatório. Suponha-se que um órgão de auditoria estabeleça como meta a melhoria do desempenho e acredite que a organização deva possuir soluções de implementação própria. Essa posição deveria, ao menos, valorizar a realização de consultas junto aos auditados, talvez até mesmo junto àqueles inseridos em estruturas burocratizadas. Essas consultas podem contemplar termos de referência para a auditoria, validação de dados e inferências sobre o desempenho, identificação de causas de problemas de desempenho e a busca de suas soluções. Assim, para se atingir o objetivo de promover a melhoria do desempenho, parece necessário o estabelecimento de uma relação mais próxima entre auditores e auditados do que aquela tradicionalmente observada (Trodden, 1995). ${ }^{27}$ 
O compromisso com a melhoria do desempenho parece ser pouco freqüente, apesar de os dados sobre esse tema não terem sido colhidos de forma sistemática neste estudo. Com essa premissa, passamos a desenvolver argumentos explicativos referentes a modelos de processos institucionais típicos (Scott, 1995). Um tipo de explicação possível é de natureza normativa: a categoria profissional de auditores públicos exerce pressão normativa para limitar o papel da EFS àquele de fortalecimento dos laços de accountability, já os profissionais da área de avaliação pública adotam tal postura para restringir-se a dizer a verdade ao poder. O outro lado da moeda consiste na aceitação de que a gestão da mudança é função e responsabilidade dos níveis gerenciais. Outro tipo de explicação é de natureza cognitiva: a maioria dos responsáveis pela condução de trabalhos de auditoria atua com base em modelos mentais de mudança organizacional, em que a opinião pública constitui um poderoso fator de pressão. Uma terceira explicação seria de natureza regulamentar: o processo de alocação orçamentária favorece órgãos de auditoria que produzem grande número de relatórios, de forma que, do ponto de vista do órgão controlador, os ganhos de desempenho nas organizações auditadas e nos programas públicos consistem em temas de menor relevância.

O mesmo tipo de argumentação pode ser utilizado para explicar o que parece ser o resultado atípico: o compromisso com a melhoria do desempenho. De um ponto de vista normativo, um órgão de auditoria pode seguir uma linha doutrinária particular, como aquela advogada pela escola denominada empowerment - delegação de competência (Johnson, 1992). De um ponto de vista cognitivo, um órgão de auditoria pode ver a realização de consultas aos auditados como uma forma natural de administrar conflitos surgidos no processo da auditoria de desempenho — ou seus funcionários podem incorporar princípios da gestão pela qualidade total. Sob a ótica legal, o órgão de auditoria pode ser premiado por redirecionar recursos da auditoria tradicional de regularidade para a auditoria de desempenho e por tornar-se um instrumento de políticas governamentais voltado à melhoria do desempenho do setor público.

De acordo com os trabalhos apresentados pelos órgãos de auditoria da OCDE, o compromisso com a meta de melhoria do desempenho é observado em dois casos: a EFS da Suécia e o Inspetor-Geral para o Departamento de Assuntos de Veteranos - US Office of Inspector General (Holmquist e Barklund-Larson, 1996; Sandberg e Larsson, 1996; Trodden, 1996). Esses órgãos de auditoria estão situados no âmbito do Poder Executivo. Esse status institucional enfraquece o comprometimento com normas profissionais que demarcam claramente os papéis da auditoria e do gerenciamento. Presume-se que essa situação encoraje o órgão de auditoria a adotar os mesmos modelos cognitivos da gestão governamental professados por aqueles que exercem influência sobre a política de gestão 
pública - nesses casos, o Ministério das Finanças e a Revisão Nacio-

nal de Desempenho, respectivamente. As idéias defendidas por esses agentes influentes são de natureza pós-burocrática e, ao menos nos EUA, guardam consonância com os princípios da melhoria contínua e da delegação de poderes aos funcionários. Mecanismos regulamentares, como o processo orçamentário, estimulam a ênfase na melhoria do desempenho. Esses estudos de caso (Eckstein, 1975) sugerem que o compromisso com a melhoria do desempenho está associado à localização do órgão de auditoria no âmbito do Executivo e à adesão aos princípios de gestão pela qualidade total.

\section{Conclusões}

A difusão de doutrinas de gerenciamento público orientada a resultados vem-se refletindo na institucionalização de um novo tipo de atividade burocrática denominada auditoria de desempenho. Nem todos os tipos de revisão governamental que se enquadram dentro dessa ampla categoria são novidade, apesar de alguns deles, a exemplo das auditorias de informações de desempenho, serem de safra recente. A formulação dos conceitos nessa área do conhecimento ainda se encontra indefinida, em parte, devido à competição jurisdicional existente entre profissionais importantes da área de revisão governamental: auditoria e avaliação. Análises conceituais isentas revelam que a auditoria de desempenho normalmente exige a formulação de instrumental de julgamento, e seria, portanto, uma forma de avaliação. Como a auditoria envolve verificação em vez de avaliação, a auditoria de desempenho consiste em auditoria somente na denominação, mas não no conceito.

A institucionalização da auditoria de desempenho, como uma dimensão da atividade burocrática, afeta a atuação dos órgãos centrais de auditoria usualmente denominados EFS. Essas organizações têm suas raízes na realização de auditorias tradicionais de regularidade com a finalidade de promover a accountability de legalidade. Muitas delas já vêm realizando auditorias de eficiência há algum tempo (um tipo de auditoria de desempenho). Várias EFS têm diversificado suas ações de controle e avançado na área de avaliação de programa nas últimas décadas. Essas organizações enfrentam a questão da conveniência de expandir as atividades de auditoria de desempenho e assim realizar uma gama mais diversificada de estilos dessa espécie de auditoria. Dependendo da situação inicial em que se encontra a EFS, o compromisso com a auditoria de desempenho pode acarretar mudanças significativas, em diferentes níveis da organização, incluindo a missão institucional, as identidades profissionais, os procedimentos e o estilo de trabalho. 
Este estudo utilizou dados sobre os órgãos centrais de auditoria de 13 países da OCDE para realizar uma investigação empírica sobre o tema. Da análise dos dados, observou-se que alguns tipos de auditoria de desempenho são mais freqüentes que outros, sendo que as auditorias de eficiência são realizadas em mais países do que as de efetividade de programa. Esses resultados são consistentes com as teorias burocráticas de resistência a mudanças e de preferência por autonomia. As influências do ambiente externo, como o desenvolvimento de sistemas de gestão de desempenho, envolvendo toda a esfera governamental, ajudam a explicar a freqüência das auditorias de informações de desempenho. O presente trabalho procurou adotar uma abordagem de pesquisa orientada ao estudo de caso, recorrendo a teorias sistêmicas de gerenciamento estratégico para explicar as semelhanças entre os resultados da Austrália, Alemanha, Holanda, Suécia e dos EUA. Os órgãos centrais de auditoria nesses países realizam auditoria de eficiência, auditorias de efetividade de programa e auditorias de capacidade de gerenciamento de desempenho. As análises desenvolvidas sugerem que os resultados, nos quais a linha de produtos de auditoria de desempenho inclui auditorias de efetividade de programa, mais susceptíveis de questionamentos de natureza política, ocorrem quando o órgão de auditoria possui um relacionamento intenso com um cliente poderoso, para o qual a dicotomia política/administração não é relevante. Exemplos desse tipo de clientes são o Congresso dos EUA, a Comissão de Orçamento do Bundestag na Alemanha e o Ministério das Finanças na Suécia. Independentemente do tipo de sistema de governo, o padrão de relacionamento Executivo/Legislativo é relevante, principalmente por oferecer condições estruturais nas quais pode-se desenvolver, ou não, um relacionamento mais intenso entre o órgão de auditoria e seus clientes.

Este trabalho abre novas perspectivas de análise da implementação de auditorias de desempenho. Uma questão que se impõe seria quanto a realizar a auditoria de desempenho do tipo padronizado/fundamentado em regras por um lado ou do estilo mais específico observado nos modelos típicos de burocracias profissionais (Mintzberg, 1983: 189). Alguns órgãos de auditoria adotaram a opção mais específica, enquanto compensam os déficits de legitimidade previsíveis, buscando incorporar valores de imparcialidade, capacidade técnica e profissionalismo em suas estruturas organizacionais. Um segundo ponto seria quanto à condução de auditorias de desempenho de forma a maximizar a probabilidade de mudança nas organizações auditadas e, dessa forma, contribuir para a melhoria do desempenho no setor público. Com base nos dados disponíveis, parece mais provável que o órgão de auditoria assuma a responsabilidade pelos resultados esperados da auditoria de desempenho quando ele se posiciona dentro do Poder Executivo em um momento de forte compromisso governamental, ainda que apenas retórico, com a melhoria da gestão pública. 
* O autor agradece a George Jones, June Pallot, Helen Perry, David Shand e a dois revisores anônimos pelos comentários às versões preliminares. Este artigo reflete os trabalhos anteriores desenvolvidos pelo autor para o Public Management Service (PUMA) da Organização para a Cooperação e o Desenvolvimento Econômico (OCDE) e publicado no documento Performance Auditing and the Modernization of Government (Auditoria de Desempenho e a Modernização do Governo — OCDE, 1996). Tradução autorizada pelo autor.

1 Nota do tradutor: Neste trabalho, o termo performance auditing será traduzido como auditoria de desempenho.

2 Em junho de 1995, o PUMA organizou um simpósio sobre auditoria de desempenho, no qual participaram representantes dos Estados-membros e especialistas. O papel das organizações internacionais na construção do domínio de estudo e de sua institucionalização é discutido por Hüfner, Meyer e Naumann (1987).

3 Nota do tradutor: Optamos por manter o termo accountability em inglês, pois assim ele tem sido encontrado na literatura da área produzida no Brasil. Conforme definição do Escritório do Auditor-Geral do Canadá, accountability consiste na obrigação de responder por uma responsabilidade outorgada. Pressupõe a existência de, pelo menos, duas partes: uma que delega a responsabilidade e outra que a aceita, com o compromisso de prestar contas da forma como usou esta responsabilidade.

4 Questões administrativas são discutidas em maior extensão em Barzelay (1987).

5 A teoria dos conceitos e categorias de Lakoff é bastante conhecida na Ciência Política. Collier e Mahon (1993), por exemplo, utilizaram aspectos dessa teoria para refinar as críticas metodológicas de Sartori sobre a formação dos conceitos em política comparativa.

6 Algumas doutrinas de administração, incluindo a Qualidade Total, identificam a melhoria do desempenho como o principal objetivo da auditoria de desempenho. Como as doutrinas adeptas dessa visão não são universalmente aceitas, parece mais conveniente considerar apenas o objetivo mais pacífico de aceitação, o de accountability de desempenho. Assim, a melhoria do desempenho como um objetivo é aqui considerada uma questão empírica e não conceitual.

7 O autor consultou ainda artigos escritos para o simpósio pelos funcionários dos órgãos centrais de auditoria, muitos dos quais oferecem informações adicionais sobre as atividades de revisão de suas organizações.

8 Przeworksi (1987) poderia sugerir que esses casos garantem uma fiscalização rigorosa, uma vez que não guardam consistência com expectativas do tipo Bayesiana.

9 A coleta de informações de países que não responderam ao questionário permitirá fornecer observações capazes de confirmar se a teoria de política pública e governança denominada família de nações, recentemente proposta, aplica-se ao domínio da gestão do setor público (Castles, 1993).

${ }^{10}$ Com efeito, consideram-se os objetivos dos programas, neste caso, como definidos no estágio de produto e não no de impacto.

${ }^{11}$ Esse subtipo partilha algumas propriedades com o conceito de auditoria sistêmica que aparece em Shand e Anand (1996), Glynn (1996), Leeuw (1996) e Hepworth (1996). Os autores acima citados consideram que as auditorias de capacidade de desempenho seriam um subtipo da auditoria sistêmica, cuja propriedade principal seria que o julgamento substantivo não é passado à efetividade dos programas ou à eficiência de processos específicos. Esses autores entendem que as auditorias sistêmicas, por sua vez, tem 
propriedades em comum com as auditorias em geral. Essa posição é contrária àquela aqui assumida, que não considera as auditorias de desempenho como um tipo de auditoria, como discutido no tópico anterior.

${ }^{12}$ Os problemas de pesquisa encontrados na tentativa de inferir uma capacidade são discutidos em Weaver e Rockman (1993: 6).

${ }^{13}$ Palestra proferida por Stephen Nicklen, Diretor de Auditoria da Comissão de Auditoria da Inglaterra e País de Gales, proferida na London School of Economics, em maio de 1996.

${ }^{14}$ Entrevista com Gerald Pedersen, Assistente do Inspetor-Geral, Ministério do Trabalho dos Estados Unidos, Washington, DC, maio de 1993. Trodden (1996) menciona o mesmo conceito.

${ }^{15}$ A revisão geral de gestão tem sido um tipo de auditoria de desempenho realizado pelo GAO. Para uma breve discussão sobre o tema, veja NAPA (1994).

${ }^{16}$ As informações que indicam que o órgão central de auditoria estaria autorizado a realizar um tipo de auditoria de desempenho, mas não realizou, foi codificada como se a linha de produtos dessa EFS não incluísse esse tipo de auditoria de desempenho. Quando um país-membro possui mais de um órgão responsável pela auditoria governamental, como ocorre nos países escandinavos, aquele com a maior capacidade operacional foi considerado o órgão central de auditoria para fins da análise aqui conduzida.

17 Até mesmo na Alemanha, um dos países mais legalistas, a eficiência tem sido considerada meta prioritária por décadas.

${ }^{18} \mathrm{O}$ mesmo se aplica às auditorias sistêmicas, categoria já discutida na nota no 11 .

${ }^{19}$ Isso foi discutido sobre o $G A O$ no período de 1960 e 1970 (Walker, 1986).

${ }^{20}$ Outros tipos de teoria de gestão estratégica, de acordo com o prático esquema de classificação de Whittington (1993: 2), são a clássica, a processual e a evolutiva. Destes tipos, a mais centrada no ator e voluntarista é a abordagem clássica, associada com Chandler (1982) e Andrews (1971). Bons exemplos no setor público seriam Moore (1995) e Heymann (1987). Se a concepção da presente pesquisa tivesse considerado um número menor de casos em maior profundidade, a escolha das propriedades relevantes poderia ter sido guiada pela teoria clássica de gerenciamento estratégico, enfatizando as variáveis internas como compromissos doutrinários dos executivos, metas de política e aspectos ambientais. Para uma discussão geral da complexidade dos diferentes tipos de modelos de políticas públicas, veja Lane (1990).

${ }^{21}$ Os achados das pesquisas comparativas baseadas em análise de casos têm sempre essa característica. Ragin (1987: 49) atribui esse padrão à prevalência de causas conjunturais múltiplas.

22 As formas de relacionamento do $G A O$ com seus clientes consistiram em uma evolução natural decorrente do posicionamento da EFS no Poder Legislativo, determinado pelo Budget and Accounting Act, de 1921. A diversificação, que representou o afastamento das auditorias tradicional e de eficiência, foi parte de uma decisão estratégica tomada nos anos 60 (Walker, 1986) que necessariamente contou com apoio parlamentar. O desenvolvimento da parceria entre o Tribunal de Contas da Alemanha e a comissão de orçamento do Bundestag seria interessante ser explorado.

${ }^{23}$ Entrevistas com funcionários anônimos do NAO, Londres, março de 1993. Para um estudo de caso do processo de trabalho do NAO, veja Roberts e Pollitt (1994: 534 ). Eles relatam que: "Todos os relatórios de auditoria do tipo value-for-money do NAO têm que ser aprovados pela autoridade máxima do $N A O$ quanto pelo Secretário-Geral do órgão auditado. Entretanto, esse relatório específico levou um longo tempo para ser aprovado (...) Houve nove minutas antes que o documento fosse finalmente aprovado e liberado para publicação em outubro de 1991".

${ }^{24} \mathrm{O}$ país que mais provavelmente questionaria esse padrão seria a Austrália. O sistema de governo, no nível federal, sofre grande influência do modelo de Westminster (inglês), e a EFS australiana não está inserida no Poder Executivo. Entretanto, o $N A O$ realiza auditorias 
de efetividade de desempenho. Um estudo de caso sobre a Austrália seria recomendável, tomando como base as críticas metodológicas de Przeworski.

${ }^{25}$ Essa posição é defendida em outro contexto por Mashaw (1983), que reconhece os potenciais déficits de legitimidade de três processos de decisão genéricos, incluindo os modelos particularistas de tratamento profissional e julgamento moral (ou equiidade). Sloan (1995) afirma que alguns interessados nos trabalhos de auditoria de desempenho irão exigir garantias quanto à observação do devido processo legal, à imparcialidade ou integridade da auditoria, e ele acredita que alguns tentarão ainda usar a justiça para obter informações reservadas dos processos de auditoria de desempenho.

${ }^{26}$ Algumas estratégias para administrar o problema retórico de demonstrar neutralidade e capacidade técnica são discutidas em Roberts (1995).

${ }^{27} \mathrm{O}$ mesmo pode ser dito para o padrão tradicional de avaliação.

\section{| Referências bibliográficas}

ANDREws, Kenneth R. (1971), The Concept of Corporate Strategy. Homewood, Ill.: Richard D. Irwin.

BARZELAY, Michael. (1992), Breaking Through Bureaucracy: A New Vision for Managing in Government. Berkeley: University of California Press.

Boyle, Richard. (1989), Managing Public Sector Performance: A Comparative Study of Performance Monitoring Systems in the Public and Private Sectors. Dublin: Institute of Public Administration.

CAStLes, Francis G. (ed.). (1993), Families of Nations: Patterns of Public Policy in Western Democracies. Aldershot, Hants: Dartmouth.

CHANDLER, Alfred. (1962), Strategy and Structure: Chapters in the History of the American Industrial Enterprise. Cambridge, MA: Harvard University Press.

Chelimsky, Eleanor. (1985), "Comparing and Contrasting Auditing and Evaluation: Some Notes on Their Relationship". Evaluation Review, august, p. 483-503.

Collier, David; Mahon, J.E. (1993), “'Conceptual Stretching' Revisited — Adapting Categories in Comparative Analysis". American Political Science Review, december, p. 845-855.

DAHL, Robert A. (1981), Democracy in the United States. Boston: Houghton Mifflin.

DeRTHICK, Martha. (1979), Policymaking for Social Security. Washington, DC: Brookings.

Eckstein, Harry. (1975), "Case Study and Theory in Political Science", in Greenstein, Fred I., Polsby, Nelson W. (eds.), Handbook of Political Science - Political Science: Scope and Theory. Reading, MA: Addison-Wesley.

Glynn, John J. (1996), Public Sector Management Reform, Changing Accountabilities, and the Role of Performance Audit.Performance Auditing and Public Sector Modernization. Paris: OECD.

Gray, Andrew; Jenkins, Bill; Segsworth, Bob. (1993), Budgeting, Auditing, and Evaluation: Functions and Integration in Seven Governments. New Brunswick, NJ.: Transaction Publishers.

Hellstern, Gerd-Michael. (1991), "Generating Knowledge and Refining Experience: The Task of Evaluation", in Kaufmann, Franz-Xavier (ed.), The Public Sector: Challenge for Coordination and Learning. Berlin: Walter de Gruyter. 
Hepworth, Noel P. (1996), "The Role of Performance Audit". In Performance Auditing and Public Sector Modernization. Paris: OECD.

Holmquist, Jörgen; UlriKa, Barklund-Larson. (1996), “The New Public Management, Performance Auditing, and How the Auditors Can Contribute to Performance Improvement". In Performance Auditing and Public Sector Modernization .Paris: OECD.

Hood, Christopher C. (1986), Administrative Analysis. Brighton: Wheatsheaf. . (1991), "A Public Management for All Seasons?". Public Administration. 69: 3-19.

. (1996), "Bureaucratic Regulation and New Public Management in the UK: Mirror Image Developments?'. Bureaucratic Gamekeeping Discussion Paper $n^{\circ}$ 2. London: London School of Economics.

Hood, Christopher C., JACKson, Michael. (1991), Administrative Argument. Aldershot, Hants: Dartmouth.

Johnson, H. Thomas. (1992), Relevance Regained: From Top-down Control to Bottom-up Empowerment. New York: Maxwell Macmillan International.

LaKofF, George. (1987), Women, Fire, and Dangerous Things: What Categories Reveal about the Mind. Chicago: University of Chicago Press.

LANE, Jan-Erik. (1990), Institutional Reform: A Public Policy Perspective. Aldershot, Hants: Gower.

Leeuw, Frans. (1996), "Performance Auditing, New Public Management, and Performance Improvement: Questions and Challenges". In Performance Auditing and Public Sector Modernization. Paris: OECD.

Light, Paul C. (1993), Monitoring Government: Inspectors General and the Search for Accountability. Washington, DC: Brookings.

Mashaw, Jerry L. (1983), Bureaucratic Justice: Managing Social Security Disability Claims. New Haven, CT: Yale University Press.

Mashaw, Jerry L., HaRfst, David L. (1990), The Struggle for Auto Safety. Cambridge, MA: Harvard University Press.

Metcalfe, Les; Richards, Sue. (1990), Improving Public Management. London: Sage.

MEYER, John W., Rowan, Brian. (1991), "Institutionalized Organizations: Formal Structure as Myth and Ceremony", in Powell, Walter W., DiMAgGio, Paul J. (eds.), The New Institutionalism in Organizational Analysis. Chicago: University of Chicago Press.

MintzBERG, Henry. (1983), Structure in Fives: Designing Effective Organizations. Englewood Cliffs, NJ: Prentice-Hall.

Moore, Mark H. (1995), Creating Value in the Public Sector: Strategic Management in Government. Cambridge, MA: Harvard University Press.

NAPA. (1994), "The Roles, Mission, and Operation of the U.S. General Accounting Office". Report Prepared for the Committee on Governmental Affairs, U.S. Senate, by the National Academy of Public Administration, october.

PATERSOn, William E., SOUtHern, David. (1991), Governing Germany. Oxford: Blackwell.

PoRTER, Michael E. (1985), Competitive Advantage: Creating and Sustaining Superior Performance. New York: Free Press.

Powell, Walter W., DiMaggio, Paul J. (1991), "The Iron Cage Revisited: Institutional Isomorphism and Collective Rationality", in Powell, Walter W., DiMagGio, Paul J. (eds.), The New Institutionalism in Organizational Analysis. Chicago: University of Chicago Press.

PrZeworski, Adam. (1987), "Methods of Cross-National Research, 1970-83: An Overview", in Dierkes, M., Weiler, H. N., Antal, A.B. (eds.), Comparative Policy Research: Learning from Experience. Aldershot, Hants: Gower.

RaGin, Charles C. (1987), The Comparative Method: Moving Beyond Qualitative and Quantitative Strategies. Berkeley, CA: University of California Press. 
RIst, Ray C. (1989), "Management Accountability: The Signals Sent by Auditing and Evaluation". Journal of Public Policy, 9, 3: 355-369.

RoBerTs, Alasdair. (1995), “'Civic Discovery' as a Rhetorical Strategy”. Journal of Policy Analysis and Management, 14, 2: 291-307.

Roberts, Simon; Pollitt, Christopher. (1994), "Audit or Evaluation? A National Audit Office VFM Study”. Public Administration, Winter, p. 527-549.

SANDBERG, Bo; LARSSON, Kjell. (1996), "The Role of Auditing in Performance Improvement". In Performance Auditing and Public Sector Modernization. Paris: OECD.

SCHAUER, Frederick. (1991), Playing by the Rules. Oxford: Clarendon.

Scoтt, W. Richard. (1995), Institutions and Organizations. Thousand Oaks, CA: Sage.

SEDGWICK, Steve. (1993), "When Does an Audit Become an Evaluation?". Canberra Bulletin of Public Administration, september, p. 148-151.

SelzNICK, Philip. (1957), Leadership in Administration: A Sociological Interpretation. New York: Harper and Row.

Senge, Peter M. (1990), The Fifth Discipline: The Art and Practice of the Learning Organization. New York: Doubleday.

Shand, David; Anand, Paul. (1996), "Performance Auditing in the Public Sector: Approaches and Issues in OECD Member Countries". In Performance Auditing and Public Sector Modernization. Paris: OECD.

STACEY, Ralph D. (1993), Strategic Management and Organisational Dynamics. London: Pitman.

Stewart, J. D. (1984), "The Role of Information in Public Accountability", in Hopwood, Anthony; Tomkins, Cyril (eds.), Issues in Public Sector Accounting. Oxford: Philip Allan.

Trodden, Stephen A. (1996), "The Objectives and Performance of Performance Auditing: The Perspective of a United States Inspector General". In Performance Auditing and Public Sector Modernization. Paris: OECD.

W ALKER, Wallace Earl. (1986), Changing Organizational Culture: Strategy, Structure, and Professionalism in the U.S. General Accounting Office. Knoxville: University of Tennessee Press.

Walsh, Annmarie H. (1996), "Performance Auditing and Legislative Oversight in the Context of Public Management Reform". In Performance Auditing and Public Sector Modernization. Paris: OECD.

Weaver, R. Kent; Rockman, Bert A. (1993), Do Institutions Matter? Government Capabilities in the United States and Abroad. Washington, DC: Brookings.

Whiтtington, Richard. (1993), What is Strategy — and Does it Matter?. London: Routledge. Wilson, James Q. (1989), Bureaucracy. New York: Basic Books.

ZAVELBERG, Heinz Günter. (1996), "Legislatures and Performance Auditing”. In Performance Auditing and Public Sector Modernization. Paris: OECD. 


\section{Resumo \\ Resumen \\ Abstract}

\section{Instituições centrais de auditoria e auditoria de desempenho: uma análise comparativa das estratégias organizacionais na OCDE \\ Michael Barzelay}

A nova gestão pública oferece um arcabouço teórico para ampliar a competência legal das instituições de auditoria governamental de forma a incluir a auditoria de desempenho. Este artigo examina questões conceituais, empíricas e administrativas suscitadas pela auditoria de desempenho. Conceitualmente, a auditoria de desempenho é termo dúbio para uma classe de atividades de revisão predominantemente avaliativas. Empiricamente, observa-se que os principais órgãos de auditoria dos países-membros da OCDE apresentam variações quanto aos tipos específicos de auditorias de desempenho realizadas. A explicação dessas variações permite algumas incursões na política contemporânea de gerenciamento público. Do ponto de vista administrativo, os órgãos de auditoria cujos mandatos legais incluem a auditoria de desempenho confrontam-se com duas questões estratégicas principais: realizar essas revisões avaliativas na modalidade tradicional de auditoria ou direcionar seu trabalho para promover a melhoria do desempenho nos órgãos auditados.

\section{Instituciones centrales de auditoría y auditoría de desempeño: un análisis comparativo de las estrategias organizativas en la OCDE \\ Michael Barzelay}

La nueva gestión pública ofrece una estructura teórica para ampliar la competencia legal de las instituciones de auditoría gubernamental como forma de incluir la auditoría de desempeño. Este artículo examina cuestiones conceptuales, empíricas y administrativas suscitadas por la auditoría de desempeño. Conceptualmente, la auditoría de desempeño es un término ambiguo para una clase de actividades de revisión predominantemente evaluativas. Empíricamente, se observa que los principales órganos de auditoría de los países miembros de la OCDE presentan variaciones con relación a los tipos específicos de auditorías de desempeño realizadas. La explicación de esas variaciones permite algunas incursiones en la política contemporánea de administración pública. Desde el punto de vista administrativo, los órganos de auditoría cuyos mandatos legales incluyen la auditoría de desempeño se confrontan con dos cuestiones estratégicas principales: realizar esas revisiones de evaluación en la modalidad tradicional de auditoría u orientar su trabajo para promover la mejoría del desempeño en los órganos auditados.

\section{Central audit institutions and performance auditing: a comparative analysis of organizational strategies in the OECD}

\section{Michael Barzelay}

The new public management supplies a rationale for broadening the mandate of external audit institutions to encompass performance auditing. This article examines conceptual, empirical and managerial issues raised by external performance auditing. Conceptually, performance auditing is a misnomer for a class of mainly evaluative review activities. Empirically, OECD countries vary in terms of the specific types of performance audits conducted by their principal external audit bodies. Explaining such variation offers some insight into the contemporary politics of public management policy. Managerially, audit bodies whose mandate includes performance auditing confront two major strategic issues: whether to conduct such evaluative review sinan auditing style and whether to gear their work to achieving performance improvement in auditee organizations.
Revista do

Serviço

Público

Ano 53

Número 2

Abr-Jun 2002

Michael

Barzelay é professor da London School of Economics and Political Science, Reino Unido.

Contato: m.barzelay@ $\underline{\text { lse.ac.uk }}$ 